\title{
Usos e abusos da obra de Hans Ulrich Gumbrecht: o caso do esporte espetáculo
}

\author{
Luiz Guilherme Burlamaqui | Universidade de São Paulo \\ Doutorando em História Social pela Universidade de São Paulo. Bolsista da FAPESP. \\ E-mail: luiz_burlamaqui@hotmail.com
}

Resenha de Esporte e mídia: a contribuição de Hans-Ulrich Gumbrecht. HELAL, Ronald \& AMARO, Fausto (Org.). RJ: EdUerj, 2014.

Hans Ulrich Gumbrecht é uma figura conhecidíssima no cenário acadêmico brasileiro. Alemáo radicado nos Estados Unidos, onde leciona em Stanford desde 1989, o filósofo costuma vir regularmente ao Brasil. Neste ponto, parte significativa de seus trabalhos encontram-se traduzidos no Brasil, e merece destaque o fato de que Gumbrecht escreve regularmente para o jornal Folha de São Paulo. No que diz respeito à relação entre estudos de mídia e esporte, Gumbrecht é uma referência incontornável. Na contramão de um certo espirito de corpo intelectual, que nega a importância dos esportes modernos, Gumbrecht tomou o fenômeno esportivo a sério. Mais do que isso, em contraponto à chamada teoria crítica do esporte, reprodutora, em larga medida, da associação entre esporte e alienaçáo, Gumbrecht faz um ode ao esporte, um exercício de louvor à beleza atlética. Longe da caricatura do fenômeno esportivo como um espaço destinado ao consumo de fanáticos abobalhados, o filósofo aproxima os esportes modernos à religião, ao sagrado e à arte, como local de produção encantamento e de fascinação.

Faltava, ainda assim, uma avaliação pormenorizada da obra, capaz de examinar tanto a sua potencialidade quanto (por que náo?) os seus limites. Publicada pela Editora da UERJ, a coletânea organizada por Fausto Amaro e Ronaldo Helal, Esporte e midia: a contribuição de Hans-Ulrich Gumbrecht, responde essa demanda. No total, são dez artigos (e doze autores) comentando a obra de Gumbrecht, e enunciando possibilidades, trajetos e caminhos de pesquisa traçados a partir de seus escritos. Como se vê pela própria dupla de organizadores, a composição de autores hibridiza jovens promessas a autores consagrados. Formado em sociologia pela New York University, Ronaldo 
Helal é uma figura aclamada no campo da comunicação e do esporte, quer seja pela sua obra, quer seja pelo papel de "organizador" do campo intelectual, com a orientação de dezenas de trabalhos na área, além da coordenação do LEME (Laboratório de Estudos de Mídia e Esporte). Numa área hegemonizada pelos estudos de futebol, Fausto desponta como acadêmico promissor, entre outras razôes, por ser um dos raros que se dedicam à decifração dos Jogos Olímpicos.

Unidade teórico-metodológica e pluralidade temática, talvez seja essa a tônica do livro organizado Amaro e Helal. Ao correr do livro, a obra de Gumbrecht é reconvertida numa verdadeira agenda de estudos para o esporte e comunicaçáo, o que dá o tom da riqueza da obra do filósofo alemão. No artigo dos organizadores, os autores chegam a enunciar uma lista de sete problemáticas que podem ser construídas a partir da obra de Hans Ulrich Gumbrecht. Isto posto, deve-se destacar que boa parte dos capítulos acabam por seguir essa agenda empírica extremamente inovadora, à exceção de uma meia dúzia, com um sabor mais teorizante. À semelhança de Bruno Latour, Gumbrecht é um crítico do modus operandi habitual das ciências humanas, fundadas numa abordagem essencialmente hermenêutica. Em revanche, Gumbrecht quer produzir uma ciência humana capaz de compreender as sensaçóes, os sentidos, o movimento, enfim, a materialidade ou a substância das relações sociais. "É um equívoco crer", disse Gumbrecht, "que as humanidades e as artes devam lidar exclusivamente com fenômenos constituídos de significação e não com fenômenos baseados na substância”, em artigo que abre o livro, Perdido na intensidade da concentração.

Concordemos ou não com as proposiçôes de Gumbrecht, o mérito desse deslocamento do olhar é o de alargar o conjunto de objetos habitualmente trabalhados pelos sociólogos, antropólogos e comunicólogos. Para o esporte, fenômeno essencialmente ligado às sensaçóes e à experiência sensível, as ilaçóes de Gumbrecht funcionam como uma luva. Um excelente exemplo das potencialidades abertas por Gumbrecht é o capítulo sobre os "sons do estádio", escrito por Pedro da Silva Marra. Ora, Pedro espalhou gravadores no espaço do estádio, e tentou captar a relação entre estética torcedora e a experiência sonora do estádio. Nesse sentido, é possível imaginar quais as dificuldades de se pensar as ligaçóes entre o som e o sentido, esboçada nos estádios. Amaro e Gazinski escreveram um belo artigo refletindo sobre como interagem torcedores, espaço esportivo e redes sociais, tomando como paradigma o Instagram, pensado à luz da teoria gumbrechtiana como "produtor de presença".

Além de abrir novos flancos, a teoria de Gumbrecht presta-se bem a revigorar temas clássicos do estudo da comunicação. Um achado, neste ponto, é o capítulo de Acker sobre a relação entre cinema, estética e esporte no caso brasileiro. Partindo de conceitos gumbrechtianos, Acker discutiu um tema muito importante para a historiografia do esporte no Brasil: a relação entre memórias, narrativas e produção midiática. Na tentativa de estabelecer relaçôes entre narrativa fílmica e a obra de Gumbrecht, Telles trilha caminho similar ao de Ecker, pensando o fascínio televisivo provocado pelo rosto do craque. Quando nada acontece em campo, produz-se uma espécie de tempo 
morto, a televisão não se furta a focalizar o grande jogador a desfilar pelo campo. É digno de nota, entretanto, que nenhum dos autores tenha dialogado com o excelente texto de Barbara Laborde (2015), Zidade, um retrato do século XXI, que se encontra, inclusive, versado para o português. Laborde resenhou o filme homônimo, um exercício de vídeo-arte do cineasta Gordon e Pareno, que, durante noventa minutos, numa partida do Real Madrid, esqueceram o jogo, e dissecaram Zidane. Trata-se de um filme de 90 minutos, que esquece, por assim dizer, a narrativa do jogo, enquanto drama coletivo, e focaliza na figura do craque. A análise de Laborde é bastante parecida com à de Telles, e a sua ausência na bibliografia é muito sentida.

De qualquer forma, o tema da relação entre esporte e arte talvez seja a bússola da teoria gumbrechtiana. Neste ponto, destacam-se a contribuição de Filipe Mostaro, que discute o fascínio propiciado pela "amarelinha" a partir das trajetórias de Pelé e Garrincha, e a de Victor Melo, que discutiu a relação entre arte vanguardista (no caso, o futurismo) e a estética dos esportes contemporâneos.

Outros capítulos, como já frisamos, possuem um corte mais teórico-epistemológico. O de Anderson Martins Gomes dos Santos póe Gumbrecht em diálogo com a chamada Escola de Frankfurt, em particular, a obra de Walter Benjamin e de Theodor Adorno. A influência dos dois autores é inegável: basta pensar, por exemplo, na verossimilhança entre a noção de "aura" em Benjamin e a de "fascínio" em Gumbrecht. As divergências, por sua vez, são igualmente flagrantes, uma vez que o elogio ao esporte encontra-se nas antípodas da teoria desencantada da realidade, proposta por Adorno e Horkheimer. Sentimos falta de um diálogo mais intenso por parte de Santos com a grande bibliografia esportiva sobre Adorno, em particular, o filosofo Bero Rigauer, que, nos anos 1970, escreveu o livro mais importante sobre o assunto, Sport und arbeit [1981, com tradução em inglês]. Já o capítulo de Araújo discute o impacto da obra de Gumbrecht para pensar a ligação entre estética, (pós) modernidade e comunicação. Nesse sentido, as ideias de Gumbrecht são postas vis-à-vis a de autores como Maffesoli ou o próprio Giddens.

Nessa linha mais teórico metodológica, um dos pontos altos do livro é o diálogo que Arlei Damo faz entre a obra de Gumbrecht e uma certa tradição da antropologia das práticas esportivas. Neste quesito, a obra de Gumbrecht afasta-se, aproxima-se e (cremos) complementa-se a obra do antropólogo Clifford Geertz, e seria muito interessante pô-las em dialogo. Os próprios termos pinçados pelos autores guardam relação entre si: enquanto Gumbrecht remete à intensidade dos esportes modernos; Geertz disserta sobre a profundidade dos jogos tradicionais. Assim como o filosofo alemão, o antropólogo americano comparou a briga de galos em Bali à experiência estética ocidental, proporcionada, neste caso, pela literatura contemporânea. São “dramas”, escreveu Geertz, "uma imagem, uma ficção, um modelo, uma metáfora, a briga de galos é um meio de expressão.” (1978, p 321) No caso de Geertz a comparação se limitava ao fato de que ambos podem ser interpretados como textos, elementos-chave de decifração de uma cultura.

As divergências são aí iniciadas: a mbos enxergam o esporte como uma 
atividade desinteressada, um fim em si mesmo. Ainda assim, os jogos, para Geertz, são produtores de significação, janelas de compreensão do tecido social, enquanto para Gumbrecht os jogos representam uma disjunção em relação à vida cotidiana, daí a sua relevância. No confronto entre Gumbrecht e Geertz, o que se dramatiza é a própria oposição entre dois tipos diferentes de abordagem em ciência social: a hermenêutico e a neossubstancialista. Damo, certamente mais perto de Geertz do que Gumbrecht, elogia o fato de que a obra do filosofo alemão seja singular, por tomar como ponto de partida a dimensão estética. Embora Damo acredite que o ponto de partida "estético" sobre o qual Gumbrecht disserta seja acertado, o antropólogo propóe um "deslocamento do olhar". Ao contrário do que pensa Gumbrecht, a beleza do jogo não é derivada de movimentos corporais autenticamente belos, e sim movimentos corporais reconhecidos pelo público como esteticamente agradáveis. Na visão de Damo, o paradoxo é que quem cria a arte, neste ponto, não são os artistas, mas o próprio público que a aprecia.

Por fim, o livro de Amaro e de Helal é destinado tanto aos neófitos quanto aos experimentados nos textos de Gumbrecht. À diferença de outros livros de teor semelhante, deve-se outra vez saudar a opção pela mescla entre empiria e teoria. Afinal, como diria Loic Wacquant, a prova do pudim teórico consiste em comê-lo, e a obra de Gumbrecht foi aprovada (com louvor!) no teste empírico. Pouco a pouco, seus textos vêm sendo mastigados pelos estudiosos brasileiros. Aos que desejam compreender o esporte espetáculo, o livro de Helal e Amaro parece não deixar dúvidas de que o sabor é adocicado.

\section{Referências bibliográficas}

GEERTZ, Clifford. "Notas sobre a briga de galos balinesa”. In: A interpretação das culturas. Rio de Janeiro, Jorge Zahar Editor, 1978.

LABORDE, B. "Zidane, um retrato do século XXI” In: HOLLANDA, B.B; BURLAMAQUI, L.G. Desvendando o jogo: nova luz sobre o futebol. Rio de Janeiro, Editora da Universidade Federal Fluminense, 2014.

RIGAUER, B. Sport and work. New York: Columbia University Press, 1981. WACQUANT, Loïc. "Esclarecer o habitus". Revista Educação \& Linguagem, ano 10, n.16. 63-71. Jul- Dez, 2007 